\title{
Baseline Sensitivity of Natural Population and Resistance of Mutants in Phytophthora capsici to Zoxamide
}

\author{
Yang Bi, Xiaolan Cui, Xiaohong Lu, Meng Cai, Xili Liu, and Jianjun J. Hao
}

First, second, third, fourth, and fifth authors: Department of Plant Pathology, China Agricultural University, Beijing, 100193, China; and third and sixth authors: Michigan State University, East Lansing 48824.

Accepted for publication 7 April 2011.

\section{ABSTRACT}

Bi, Y., Cui, X., Lu, X., Cai, M., Liu, X., and Hao, J. J. 2011. Baseline sensitivity of natural population and resistance of mutants in Phytophthora capsici to zoxamide. Phytopathology 101:1104-1111.

Laboratory experiments were conducted to determine the baseline sensitivity of Phytophthora capsici and its risk for developing resistance to zoxamide. In total, $158 \mathrm{P}$. capsici isolates were collected from China. All 158 isolates were sensitive to zoxamide, with effective concentrations for $50 \%$ inhibition of mycelial growth of 0.023 to $0.383 \mu \mathrm{g} / \mathrm{ml}$ and a mean of $0.114 \mu \mathrm{g} / \mathrm{ml}$, which showed a skewed unimodal distribution. Zoxamide-resistant mutants of $P$. capsici were obtained by either treating mycelial culture and zoospores with ultraviolet irradiation or adapting a culture on zoxamide-amended plates. The frequency of resistance selection averaged $1.8 \times 10^{-7}$. Resistant isolates were also derived by selfing or crossing two sexually compatible isolates, resulting in a mean selection frequency of 0.47 . The resistance factor (RF) for zoxamide was 25 to 100 in $P$. capsici mutants. Through 10 culture transfers, the mutants maintained high levels of RF (between 14 and 134) and had almost equal fitness as their wild-type parents in mycelial growth, sporulation, and virulence. There was no cross resistance between zoxamide and either flumorph, metalaxyl, azoxystrobin, or etridiazole. Based on the results above, $P$. capsici can develop resistance to zoxamide, and the risk is predicted to be moderate in nature.
Phytophthora capsici Leonian is a destructive oomycete plant pathogen with worldwide distribution, and can cause severe diseases on root, crown, fruit, and foliage in many economically important crops such as pepper, watermelon, cucumber, pumpkin, tomato, and snap bean $(4,11,13,23)$. $P$. capsici is a soil inhabitant, and can spread through soil and water movement $(12,25)$, which makes disease management difficult. Application of chemical fungicides is one of the effective ways of managing diseases caused by $P$. capsici. However, the risk of losing the effectiveness due to development of fungicide resistance has compromised the control strategy. For example, metalaxyl or mefenoxam and other phenylamide fungicides, which are highly effective against many oomycetes, have been frequently reported to lose their effectiveness at certain levels of frequencies due to the development of resistance in populations in many oomycetes $(15,18,20,21,24$, 26,28).

Zoxamide is highly effective against oomycetes, and used for foliar application on potato, vine crops, and other vegetables to control oomycete-induced diseases (10). It is also effective to true fungi such as Botrytis cinerea, Venturia inaequalis, Monilinia fructicola, Mycosphaerella fijiensis, and Cercospora beticola (10). It is the only commercially available fungicide in the benzamides group (Fungicide Resistance Action Committee [FRAC] website). The fungicide causes mitotic arrest by binding to $\beta$-tubulin, inhibiting tubulin polymerization and cell division of the pathogen (31). Via this mechanism, zoxamide does not affect initial spore germination but inhibits germ-tube elongation of the pathogen (32), which is required for penetration through host tissue. Zoxamide was developed in 1998 by Dow AgroSciences LIC (Indianapolis, IN) and has been commercialized since 2001

Corresponding authors: X. Liu; E-mail address: seedling@ cau.edu.cn; and J. Hao; E-mail address: jjhao@msu.edu

doi:10.1094/PHYTO-01-11-0010

(c) 2011 The American Phytopathological Society
(FRAC 2008). This fungicide was not registered on potato and tomato, pepper, and cucumber in China until 2009 (CCM International Ltd., Guangzhou, China website).

Before a chemical is applied widely, it is important to establish a baseline level of fungicide sensitivity in a region, such as China, for monitoring fungicide resistance in the $P$. capsici population. To date, zoxamide resistance in $P$. capsici has not been reported in the field anywhere (30), although $B$. cinerea isolates are found to be moderately and highly resistant to zoxamide in the field of Greece (19). It seems less likely for $P$. capsici to develop resistance to zoxamide compared with metalaxyl, because the latter has been frequently reported having mutant population in the field $(6,22,35)$ whereas no zoxamide resistance in the field has been reported. However, the risk of $P$. capsici for developing resistance to zoxamide should be evaluated based on the following facts: zoxamide is in the group with the same mode of action as benzimidazole fungicides, both of which are $\beta$-tubulin protein inhibitor, and benzimidazole has been overcome by some pathogens in the field $(7,9)$. The risk of fungicide resistance can be evaluated by generating fungicide-resistant mutants in the laboratory and characterizing their biological and pathogenic attributes (7). Attempts have been made to obtain highly resistant isolates to zoxamide in $P$. capsici but, thus far, there has been no success (33).

In this study, we were interested in the possibility of generating mutants of $P$. capsici to zoxamide and characterizing the biology of the derived mutants. The objectives were to (i) determine the baseline sensitivity of natural populations of $P$. capsici to zoxamide, (ii) generate mutants of $P$. capsici resistant to zoxamide, (iii) characterize fitness components of the resistant mutants, and (iv) analyze cross-resistance relationships between zoxamide and other fungicides.

\section{MATERIALS AND METHODS}

Isolates of $\boldsymbol{P}$. capsici. Pepper (Capsicum annuum Longum) plants with typical signs and symptoms of $P$. capsici infection 
were collected in 2007, 2008, and 2009 from fields of various cities and provinces in China, including Anhui, Beijing, Gansu, Hebei, Hubei, Hunan, Inner Mongolia, Shaanxi, Xinjiang, Xizang, and Yunnan, where there was no history of zoxamide applications (Table 1). All the regions above have at least 1,000 total hectares of $P$. capsici hosts, including pepper, squash, cucumber, and tomato. Pepper stems with lesions were cut into 0.5 -cm-diameter pieces, disinfected in $0.5 \%$ ( $\mathrm{vol} / \mathrm{vol}$ ) $\mathrm{NaClO}$ for $3 \mathrm{~min}$, rinsed three times with shaking in sterile water, and plated on potato dextrose agar (PDA) (200 $\mathrm{g}$ of boiled potato tubers, $18 \mathrm{~g}$ of dextrose, and $14 \mathrm{~g}$ of agar, with distilled water brought to 1 liter), amended with rifampicin (98\% a.i., $50 \mu \mathrm{g} / \mathrm{ml}$; Tuoyingfang Biotech Co., Ltd., Beijing), penicillin (98\% a.i., $50 \mu \mathrm{g} / \mathrm{ml}$; Tuoyingfang Biotech Co., Ltd), pentachloronitrobenzene (40\% a.i., $50 \mu \mathrm{g} / \mathrm{ml}$; Sanli Chemical Industry Co., Ltd., Shanxi, China), and carbendazim (98.9\% a.i., $50 \mu \mathrm{g} / \mathrm{ml}$; Guangxin Agricultural Chemicals Co., Ltd., Anhui, China). After 3 days of incubation at $25^{\circ} \mathrm{C}$ in the dark, $P$. capsici was isolated from the edge of the culture, which was transferred to a new PDA plate. In total, 158 isolates were obtained and all were transferred as single-zoospores to obtain pure cultures (17).

In addition, two standard $P$. capsici isolates, PCAS1 (original isolate code P1314, mating type A1) and PCAS2 (original isolate code P1319, mating type A2), were kindly provided by Professor Michael Coffey (University of California, Riverside) (1). These two isolates were also purified by transfer of single zoospores prior to storage. All of the cultures were maintained on PDA. For long-term storage, the culture was transferred to PDA slants, covered with sterile mineral oil, and stored at room temperature.

Fungicides. Technical-grade zoxamide $[97.5 \%$ a.i.; Gowan Company, LLC, Yuma, AZ], flumorph (92.5\% a.i.; Research Institute of Chemical Industry, Shenyang, China), metalaxyl (96\% a.i.; Agrolex P. Ltd., Beijing), azoxystrobin (95\% a.i., Syngenta Biotechnology Co. Ltd., Shanghai, China), cymoxanil (98\% a.i.; Xinyi Agrochemicals Company, Jiangsu, China), and etridiazole (92\% a.i.; Wanquan Agrochemicals Company, Hebei, China) were dissolved individually in acetone to make stock solutions. The stocks were stored at $4{ }^{\circ} \mathrm{C}$ in the dark. The final concentration of acetone in any tested agar media was limited to $0.1 \%$ ( $\mathrm{vol} / \mathrm{vol}$ ) which, in a preliminary test, was the level causing no inhibition of mycelial growth, cystospore germination, or sporangial germination of P. capsici (unpublished data). This concentration of solvent acetone was used throughout the study when fungicides were amended in agar media. Throughout this study, the same volume of acetone for dissolving fungicides was used as a control. To prepare agar plates amended with serial dilutions of zoxamide, fungicide stock solutions were added to PDA that was adjusted to $50^{\circ} \mathrm{C}$ before pouring plates.

Baseline sensitivity of $\boldsymbol{P}$. capsici to zoxamide. Mycelial growth was used to determine the sensitivity of $P$. capsici to zoxamide. For each of the 158 P. capsici isolates, a fresh plug ( $5 \mathrm{~mm}$ in diameter) was taken from the growing edge of active mycelia on PDA and transferred onto PDA amended with zoxamide at $0,0.02,0.04,0.08,0.15,0.3$, or $0.6 \mu \mathrm{g} / \mathrm{ml}$. Each treatment was replicated four times. After incubation at $25^{\circ} \mathrm{C}$ in the dark for 6 days, two measurements were taken for each colony at perpendicular angles, and the average of the two measurements was used for analysis. The diameter of the mycelial plug $(5 \mathrm{~mm})$ was subtracted from the colony diameter. A regression equation was derived by correlating the log of inhibitor concentration of zoxamide and the probit of inhibition percentage of average radial mycelial growth of $P$. capsici, and effective concentration for $50 \%$ inhibition $\left(\mathrm{EC}_{50}\right)$ of $P$. capsici was calculated from the regression equation (17). A histogram of $\mathrm{EC}_{50}$ for all 158 P. capsici isolates was plotted, and the shape of frequency distribution was analyzed by examining curve shape, range, and mean values of $\mathrm{EC}_{50}$, as well as ratio of highest and lowest values of $\mathrm{EC}_{50}$.

Generation of zoxamide-resistant mutants of $\boldsymbol{P}$. capsici. Mass selection from mycelial plugs and zoospores. In all, 2 standard strains (PCAS1 and PCAS2) and 11 Chinese strains (Hd13, Hx-1, Dz-15, N-7, Sx-13, Sy-12, Pg-1, Lx2-1, Xs-11, Hb1-21, and Z-11) of $P$. capsici were randomly picked from each region to generate zoxamide-resistant mutants. Either mycelial plugs or zoospores were treated with ultraviolet (UV) irradiation (method I) or with zoxamide taming (method II) as described below to obtain the mutants. In method I, mycelia of 5-day-old wild-type isolates were treated with UV light $(20 \mathrm{~W}, 254 \mathrm{~nm})$ at $20 \mathrm{~cm}$ in vertical distance for $30 \mathrm{~min}$ at $25^{\circ} \mathrm{C}$, followed by $30 \mathrm{~min}$ of incubation in darkness to avoid light repairing of DNA damage. A 5-day-old culture of the same isolate without UV treatment was used for a control. To select for zoxamide-resistant mutants, mycelial plugs ( $5 \mathrm{~mm}$ in diameter) were cut randomly from the UV-treated cultures using a cork borer and placed on PDA plates containing zoxamide at $30 \mu \mathrm{g} / \mathrm{ml}$ (PDZ30), with the mycelial side in direct contact with the medium. Cultures growing from the plug were subsequently transferred to PDA and used as zoxamide-resistant isolates.

Zoospore suspensions of $P$. capsici were obtained using the method described by Lamour and Hausbeck (15). Zoospore titer then was quantified with a hemacytometer before exposing the suspension to UV light $(20 \mathrm{~W}, 254 \mathrm{~nm})$ at $20 \mathrm{~cm}$ in vertical distance for $1.5 \mathrm{~min}$, followed by $30 \mathrm{~min}$ of incubation in

TABLE 1. Phytophthora capsici isolates and their sensitivity to zoxamide

\begin{tabular}{|c|c|c|c|c|}
\hline \multirow[b]{2}{*}{ Region, province ${ }^{\mathrm{x}}$} & \multirow[b]{2}{*}{ Coordinates } & \multirow[b]{2}{*}{ Number of isolates, code } & \multicolumn{2}{|c|}{$\mathrm{EC}_{50}(\mu \mathrm{g} / \mathrm{ml})^{\mathrm{y}}$} \\
\hline & & & Range & Mean \\
\hline Pinggu, Beijing & $\mathrm{E} 117^{\circ} 7^{\prime} 17^{\prime \prime} \mathrm{N} 40^{\circ} 8^{\prime} 27^{\prime \prime}$ & $13, \mathrm{Pg}-$ & $0.074-0.325$ & $0.155 \mathrm{bc}$ \\
\hline Shunyi, Beijing & $\mathrm{E} 117^{\circ} 7^{\prime} 17^{\prime \prime} \mathrm{N} 40^{\circ} 8^{\prime} 27^{\prime \prime}$ & 10, Sy- & $0.046-0.126$ & $0.084 \mathrm{bc}$ \\
\hline Dingxing, Hebei & $\mathrm{E} 115^{\circ} 43^{\prime} 31^{\prime \prime} \mathrm{N} 40^{\circ} 20^{\prime} 21^{\prime \prime}$ & 29, Hd-, Hx- & $0.027-0.192$ & $0.107 \mathrm{bc}$ \\
\hline Dingzhou, Hebei & $\mathrm{E} 115^{\circ} 43^{\prime} 31^{\prime \prime} \mathrm{N} 40^{\circ} 20^{\prime} 21^{\prime \prime}$ & $31, \mathrm{Dz}-$ & $0.048-0.168$ & $0.086 \mathrm{bc}$ \\
\hline Bayannuoer, Inner Mongolia & $\mathrm{E} 107^{\circ} 23^{\prime} 12^{\prime \prime} \mathrm{N} 40^{\circ} 45^{\prime} 58^{\prime \prime}$ & $21, \mathrm{~N}-$ & $0.023-0.129$ & $0.064 \mathrm{c}$ \\
\hline Yangling, Shaanxi & $\mathrm{E} 108^{\circ} 42^{\prime} 33^{\prime \prime} \mathrm{N} 34^{\circ} 19^{\prime} 46^{\prime \prime}$ & $19, \mathrm{Sx}^{-}$ & $0.057-0.361$ & $0.118 \mathrm{bc}$ \\
\hline Fuyang, Anhui & $\mathrm{E} 117^{\circ} 17^{\prime} 13^{\prime \prime} \mathrm{N} 31^{\circ} 51^{\prime} 57^{\prime \prime}$ & $18, \mathrm{Lx}-$ & $0.036-0.321$ & $0.115 \mathrm{bc}$ \\
\hline Lasa, Xizang & E91 ${ }^{\circ}{ }^{\prime} 27^{\prime \prime} \mathrm{N} 29^{\circ} 38^{\prime} 44^{\prime \prime}$ & $\ldots, \mathrm{Xz}-$ & 0.149 & $0.149^{\mathrm{z}}$ \\
\hline Kunming,Yunnan & $\mathrm{E} 102^{\circ} 43^{\prime} 20^{\prime \prime} \mathrm{N} 25^{\circ} 2^{\prime} 14^{\prime \prime}$ & $4, \mathrm{Xs}-$ & $0.184-0.251$ & $0.206 \mathrm{~b}$ \\
\hline Changsha, Hunan & $\mathrm{E} 112^{\circ} 56^{\prime} 20^{\prime \prime} \mathrm{N} 28^{\circ} 13^{\prime} 43^{\prime \prime}$ & 2, Fka- & $0.105-0.171$ & $0.138^{\mathrm{z}}$ \\
\hline Wuhan, Hubei & $\mathrm{E} 114^{\circ} 18^{\prime} 19^{\prime \prime} \mathrm{N} 30^{\circ} 35^{\prime} 35^{\prime \prime}$ & $4, \mathrm{Hb}-$ & $0.157-0.201$ & $0.173 \mathrm{~b}$ \\
\hline Wulumuqi, Xinjiang & $\mathrm{E} 87^{\circ} 37^{\prime} 2^{\prime \prime} \mathrm{N} 43^{\circ} 49^{\prime} 32^{\prime \prime}$ & $2, \mathrm{Ym}-$ & $0.374-0.383$ & $0.379^{\mathrm{z}}$ \\
\hline Zhangye, Gansu & $\mathrm{E} 103^{\circ} 50^{\prime} 4^{\prime \prime} \mathrm{N} 36^{\circ} 3^{\prime} 1^{\prime \prime}$ & $4, \mathrm{Z}-$ & $0.063-0.353$ & $0.192 \mathrm{~b}$ \\
\hline
\end{tabular}

${ }^{x}$ Location of sampling in China.

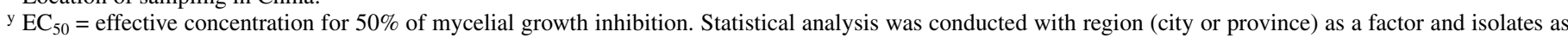
replications. Fisher's least significance difference multiple-range tests were conducted with mean EC 50 values. Values followed by same letters in the same column are not significantly different at level $\alpha=0.05$.

z Values were not compared because the sample (isolate) size was less than three. 
darkness. An aliquot of $100 \mu \mathrm{l}$ of UV-treated and an untreated zoospore suspension $\left(\approx 2.0 \times 10^{7}\right.$ zoospores $\left./ \mathrm{ml}\right)$ was plated on PDZ30. PDA plates without fungicide amendment were used as a control. The cultures were incubated at $25^{\circ} \mathrm{C}$ for 5 to 7 days in darkness, and single colonies of surviving colonies were transferred to PDZ30 plates to confirm their resistance to zoxamide.

In method II, either mycelia or zoospores of $P$. capsici isolates without UV treatment were first cultured on PDA amended with zoxamide at $2 \mu \mathrm{g} / \mathrm{ml}$, and then transferred to a series of PDA plates with increasing zoxamide concentrations in the media at each transfer: $5,10,20,30,50$, and $100 \mu \mathrm{g} / \mathrm{ml}$, with three replicate plates for per isolate. Colonies that survived the highest or final concentration of fungicides were transferred to PDZ30 plates to confirm their resistance. The experiment was done twice.

Selection from sexual progeny. In total, 111 sexual progeny (from oospores) were obtained previously in our laboratory from self-crossed PCAS1 and 107 progeny were obtained from sexual hybridization between PCAS1 and PCAS2 (17). All these sexual progeny were incubated on PDZ30 medium. After 3 to 4 days, isolates that grew on the plate were examined for zoxamide sensitivity as described above.

Characterization of zoxamide-resistant mutants. Resistance factor determination. Cultures growing on PDZ30 were transferred onto new PDA plates amended with zoxamide at concentrations of $0,1,5,10,20,30$, and $50 \mu \mathrm{g} / \mathrm{ml}$ and incubated for 4 days in darkness at $25^{\circ} \mathrm{C}$. Diameters of the colony were measured perpendicularly, and the two measurements on each plate were averaged. Effective concentration of zoxamide for $90 \%$ mycelial growth inhibition $\left(\mathrm{EC}_{90}\right)$ was determined from a dose response (zoxamide concentration and mycelial growth) regression equation. The ratio of $\mathrm{EC}_{90}$ for a resistant isolate to $\mathrm{EC}_{90}$ for the sensitive parent gave an estimation of the resistance level, or resistance factor (RF). Single-zoospore cultures of mutants were preserved for further study. RF was calculated for all zoxamideresistant isolates using the formula $\mathrm{RF}=\mathrm{EC}_{90} \mathrm{X} / \mathrm{EC}_{90} \mathrm{WT}$, where $\mathrm{EC}_{90} \mathrm{X}$ is the $\mathrm{EC}_{90}$ value of the strain being examined and $\mathrm{EC}_{90} \mathrm{WT}$ is the $\mathrm{EC}_{90}$ value of the wild-type strain of that isolate.

Resistance stability. Resistance stability of the mutants was assayed by placing the isolates on PDA plates free of fungicides, replicated with three plates per isolate and four culture plugs on each plate. Plates were incubated at $25^{\circ} \mathrm{C}$ in the dark and transferred to a new PDA plate when the colony was $\approx 8 \mathrm{~cm}$ in diameter. This procedure was repeated until a 10th transfer had been done. Colonies were measured as described previously, and $\mathrm{EC}_{90}$ values were determined as described above for the 1st and 10th subcultures. The experiment was done twice.

Mycelial growth responses to temperature. To examine the fitness of zoxamide-resistant isolates, 13 P. capsici mutants (11 from asexual and 2 from sexual selections) were compared with 2 sensitive parental strains (PCAS1 and $\mathrm{Hx}-1$ ) for mycelial growth at various temperatures, sporulation (in vitro and in vivo), cystospore germination, virulence, and oospores production. A split-plot experimental design was applied, with temperature (growth chamber) as whole-plot factor and isolates as the subplot factor. Each isolate had four replicate plates per temperature treatment. All the experiments were done twice. Temperature tolerance was tested by growing the resistant isolates and wildtype parents on PDA at $10,18,25,30$, and $35^{\circ} \mathrm{C}$ in darkness. The colony diameter of each isolate was measured perpendicularly 5 days after the incubation.

Sporangial production and cystospore germination in vitro. In vitro sporangial production of $P$. capsici was as described by Café and Ristaino with slight modification (3). Briefly, a mycelial plug was transferred from a 5-day-old culture of $P$. capsici onto V8 medium and incubated for 5 days under light (2,000 to 3,000 lux) for $48 \mathrm{~h}$ at $25^{\circ} \mathrm{C}$. To this plate, $10 \mathrm{ml}$ of sterile distilled water was added and incubated at $4^{\circ} \mathrm{C}$ for 30 to $45 \mathrm{~min}$. Zoospores were released after this process. Sporulation was quantified with a hemacytometer and expressed as the number of zoospores per square centimeter of culture, which was the average of three measurements. Cystospore germination was determined under a microscope after $12 \mathrm{~h}$ of incubation on PDA at $25^{\circ} \mathrm{C}$ in the dark. The germination percentage of cystospores (the number of germinated cystospores divided by the total number of observed cystospores) was calculated. Four replicate plates were used for each isolate.

Virulence and sporulation of $\mathrm{P}$. capsici isolates in vivo. Virulence of each $P$. capsici isolates was examined by inoculating detached leaves of bell pepper ('Tedaqiemen') with a 5-mm mycelial plug derived from the margin of a young colony on PDA. Tested isolates included eight resistant isolates derived from parent PCAS1, three from $\mathrm{Hx}-1$, and two from sexual progeny. Five leaves (the same age and position on the plants) for each $P$. capsici isolate were placed on $1 \%$ water agar in a petri dish. After incubation in a chamber (Shanghai Yiheng Technical Co., Ltd., Shanghai, China) with $80 \%$ relative humidity, as determined using the manufacturer setting, for 4 days at $25^{\circ} \mathrm{C}$ with settings of $12 \mathrm{~h}$ of light and $12 \mathrm{~h}$ of darkness, the length and width of each necrotic lesions on the leaves were measured. The lesion area was calculated as the area of an oval shape, with the lesion length and width as the long and short diameters, respectively, and used as an estimate of virulence of $P$. capsici. $P$. capsici was reisolated as described above to confirm the pathogen identity. The experiment was done twice.

Pepper plants were inoculated as described above. Four days after inoculation, five diseased leaves per isolate were placed in a $50-\mathrm{ml}$ centrifuge tube containing $15 \mathrm{ml}$ of distilled water and agitated on a vortex mixer (Kylin-Bell Lab Instruments Co. Ltd., Haimen, China) for $15 \mathrm{~s}$. Then, $10 \mu \mathrm{l}$ of the resulting droplet spore suspension was counted using a hemacytometer and the number of sporangia per square centimeter of diseased leaf surface was calculated by averaging the sporangial spore number of four droplets (subsamples) from each diseased leaf.

Mating types and oospore production of $\mathrm{P}$. capsici mutants. Before examining oospore production, the mating type of zoxamide-resistant mutants and their parents was determined using the method described by Rubin and Cohen (5). Briefly, the isolates were co-cultured with reference isolates PCAS1 (A1 mating type) and PCAS2 (A2 mating type) on 10\% V8 medium (3) in darkness for $\approx 15$ days, and with themselves as well (self-crossing). When oospores were formed, the agar medium with culture was blended in a blender to form an oospore suspension. Oospores were counted with the help of a hemacytometer, as the average of four subsamples. Each isolate had four replicates (agar plates).

Cross resistance. For both sensitive and resistant isolates of $P$. capsici, individual agar disks $(5 \mathrm{~mm})$ were removed from the edge of actively growing cultures and placed, with mycelial side facing toward contacting the media surface, on the center of a petri dish containing PDA amended with various concentrations of fungicides, including flumorph (a carboxylic acid amide fungicide), metalaxyl (phenylamide fungicide), cymoxanil (cyanoacetamideoxime fungicide), etridiazole (thiadiazole fungicide), and azoxystrobin (Qo-inhibiting fungicide). Numbers of $P$. capsici isolates for test fungicides at corresponding concentrations were as follow: 24 isolates for flumorph (at concentrations of $0.6,0.8,1,1.2,1.4$, and $1.6 \mu \mathrm{g} / \mathrm{ml}), 24$ isolates for metalaxyl (at $0.5,1.25,2.5,5,10,20$, and $50 \mu \mathrm{g} / \mathrm{ml}$ ), 16 isolates for cymoxanil (at 5, 10, 20, 40, and $80 \mu \mathrm{g} / \mathrm{ml}$ ), 24 isolates for etridiazole (at $0.2,0.4,0.6,0.8,1$, and $1.5 \mu \mathrm{g} / \mathrm{ml}$ ), and 15 isolates for azoxystrobin (at $0.05,0.1,1,2,5,10$, and $20 \mu \mathrm{g} / \mathrm{ml}$ ). After incubation at $25^{\circ} \mathrm{C}$ in the dark for 4 days, $\mathrm{EC}_{50}$ values were determined with the method described above. Each treatment had three replicate culture plates. The experiment was conducted twice.

Statistic analysis. Statistical analyses were conducted using the SAS software (version 9, SAS Inc., Cary, NC). Data of re- 
peated experiments were combined for analysis because variances between experiments were homogeneous, as determined visually by residual analysis, using a general linear model (GLM procedure). The $\mathrm{EC}_{50}$ and $\mathrm{EC}_{90}$ values for each isolate were calculated by regression analysis using the percentage of growth inhibition against the logarithmic value of fungicide concentration. $\mathrm{EC}_{50}$ values were calculated from the cross-resistance described above from the fitted regression line of the probability of percent inhibition plotted against the log-transformed fungicide concentration (2). Analysis of variance was performed using the GLM model and multiple comparisons of values were conducted using Fisher's least significance difference test on mycelial growth in the study of zoxamide resistance at the significance level $\alpha=0.05$. For effect of temperature on mycelial growth, the CONSTRAST statement was used to compare each isolate with its parental isolates.

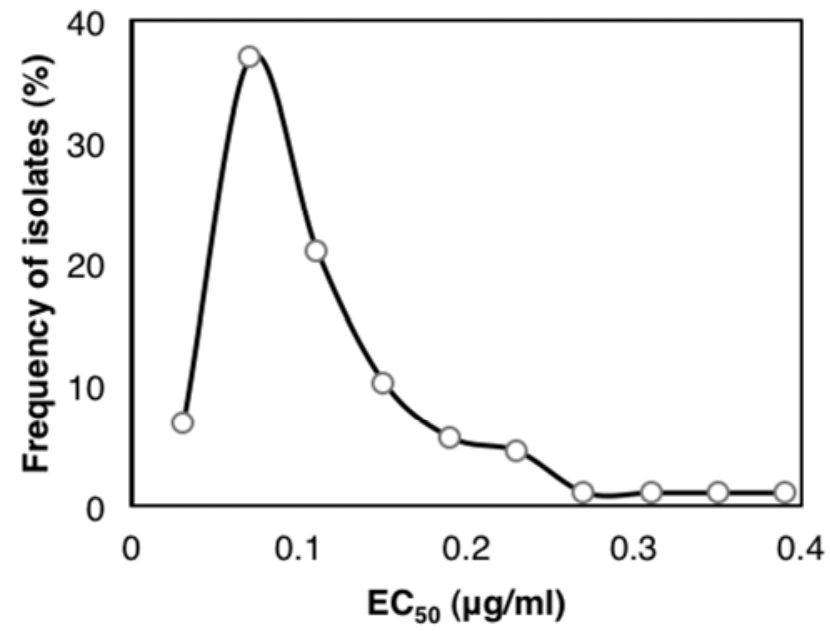

Fig. 1. Frequency distribution of effective concentration of zoxamide for $50 \%$ inhibition of mycelial growth $\left(\mathrm{EC}_{50}\right)$ of Phytophthora capsici isolates. In total, 158 Phytophthora capsici isolates were collected from areas in China that had never been exposed to zoxamide. Points shown are frequency at specific value of $\mathrm{EC}_{50}$.
Spearman rank correlation was used to quantify correlations in $\mathrm{EC}_{50}$ values between fungicides to infer cross-resistance.

\section{RESULTS}

Baseline sensitivity of $\boldsymbol{P}$. capsici to zoxamide. The frequency distribution of $\mathrm{EC}_{50}$ values for 158 field isolates (Table 1) to zoxamide showed a unimodal curve with a positive skew (Fig. 1). $\mathrm{EC}_{50}$ values for zoxamide on mycelial growth of $P$. capsici were 0.023 to $0.383 \mu \mathrm{g} / \mathrm{ml}$, with a mean of $0.114 \mu \mathrm{g} / \mathrm{ml}$. The ratio of the maximum $\mathrm{EC}_{50}$ to the minimum $\mathrm{EC}_{50}$ was 16.4. There was a difference of mean values of $\mathrm{EC}_{50}$ between some locations (provinces or city). For example, $\mathrm{EC}_{50}$ was the highest $(0.379 \mu \mathrm{g} / \mathrm{ml})$ in Wulumuqi and lowest in Bayannuoer $(0.064 \mu \mathrm{g} / \mathrm{ml})$. However, there was not a trend of $\mathrm{EC}_{50}$ distribution geographically among regions (city or province), because most of the isolates were not different from region to region in terms of $\mathrm{EC}_{50}$ (Table 1). This result indicated that no zoxamide resistance was detected in field isolates.

Generation of zoxamide-resistant mutants of $\boldsymbol{P}$. capsici. The percentage of surviving zoospores from UV treatment was $\approx 20 \%$. Eight resistant mutants, designated as RZ2-2, RZ2-6, RZ2-8, RZ3-3, RZ3-4, RZ3-5, RZ4-1, and RZ13-3, were obtained from zoospores of PCAS1 treated with UV. Two mutants, designated as RZ19-10 and RZ4-2, were obtained from zoospores of parental strain Hx-1 treated with UV. One mutant, designated as Xh38-10, was obtained from parental strain $\mathrm{Hx}-1$ by adaptation on zoxamide-amended medium (Table 2). The mutation frequency was $1.2 \times 10^{-7}$ using UV treatment and $2.4 \times 10^{-7}$ by zoxamide adaption. Therefore, the average selection frequency of asexual progeny was $1.8 \times 10^{-7}$. No resistant mutants were obtained from PCAS2 or the other 10 experimental isolates. However, among the 111 sexual progeny of PCAS1 (selfed) and 107 progeny from crossing between PCAS1 and PCAS2, 53 and 49 isolates were resistant, respectively, having mutation frequencies of 0.48 and 0.46 , respectively, and the weighted average was 0.47 . Among 13 P. capsici mutants, 4 had RF values of 24.5 to 39.3 and the others all had RF $>40$. R1-63, selected from sexual progeny of PCAS1, showed the highest resistance level $(\mathrm{RF}=147.8)($ Table 2$)$.

TABLE 2. Zoxamide sensitivity of Phytophthora capsici mutants and their parental isolates PCAS1 and Hx-1 with the 1st and 10th subcultures on fungicide-free medium

\begin{tabular}{|c|c|c|c|c|c|}
\hline \multirow[b]{2}{*}{ Origin, isolate ${ }^{\mathrm{w}}$} & \multicolumn{2}{|c|}{$\mathrm{EC}_{90}$ at the ${ }^{\mathrm{x}}$} & \multicolumn{2}{|c|}{$\mathrm{RF}$ at the ${ }^{\mathrm{y}}$} & \multirow[b]{2}{*}{$\mathrm{FSC}^{\mathrm{z}}$} \\
\hline & 1st transfer $(\mu \mathrm{g} / \mathrm{ml})$ & 10th transfer $(\mu \mathrm{g} / \mathrm{ml})$ & 1st transfer & 10th transfer & \\
\hline \multicolumn{6}{|l|}{ Asexual progeny } \\
\hline RZ4-1 & $54.26 \mathrm{~b}$ & $30.28 b^{*}$ & 92.3 & 55.1 & 0.60 \\
\hline RZ2-2 & $53.60 \mathrm{~b}$ & $21.48 c^{*}$ & 91.2 & 39.1 & 0.43 \\
\hline RZ2-6 & $47.94 \mathrm{c}$ & $29.62 b^{*}$ & 81.6 & 53.9 & 0.66 \\
\hline RZ3-5 & $23.78 \mathrm{de}$ & $7.77 \mathrm{e}^{*}$ & 40.5 & 14.1 & 0.35 \\
\hline RZ3-4 & $20.42 \mathrm{e}$ & $24.10 \mathrm{c}$ & 34.7 & 43.8 & 1.26 \\
\hline Hx-1 & $0.66 \mathrm{c}$ & $0.78 \mathrm{c}$ & - & & $\ldots$ \\
\hline RZ19-10 & $25.83 \mathrm{a}$ & $44.63 \mathrm{ab}^{*}$ & 39.3 & 57.1 & 1.45 \\
\hline Xh38-10 & $25.20 \mathrm{a}$ & $46.17 \mathrm{a}^{*}$ & 38.3 & 59.0 & 1.52 \\
\hline RZ4-2 & $16.10 \mathrm{~b}$ & $41.96 b^{*}$ & 24.5 & 53.6 & 2.19 \\
\hline \multicolumn{6}{|l|}{ Sexual progeny } \\
\hline \multicolumn{6}{|c|}{$\begin{array}{l}\text { Isolates in bold font are parents of the isolates listed under them. } \\
\text { Initial } \mathrm{EC}_{90} \text { : effective concentration for } 90 \%\left(\mathrm{EC}_{90}\right) \text { mycelial growth inhibition, with four replicates per isolate. Mean values followed by the same letter are not } \\
\text { significantly different according to Fisher's least significance difference }(\alpha=0.05) . \mathrm{EC}_{90} \text { was also compared for each isolate between the } 1 \text { st and } 10 \text { th transfers; } \\
\text { an asterisk }(*) \text { indicates significant difference. } \\
\text { RF: resistance factor, a ratio of } \mathrm{EC}_{90} \text { for a fungicide-resistant mutant relative to } \mathrm{EC}_{90} \text { for the parental isolate. } \\
\text { FSC: factor of sensitivity change, the ratio of } \mathrm{RF} \text { at the } 10 \text { th transfer over the } 1 \mathrm{st} \text { transfer. Multiple comparisons were performed within a column under each }\end{array}$} \\
\hline
\end{tabular}


Characterization of zoxamide-resistant mutants. Stability of resistance. Zoxamide resistance of the mutants varied after 10 successive culture transfers on fungicide-free media (Table 2). Zoxamide sensitivity (measured by $\mathrm{EC}_{90}$ ) was different among most of the isolates at both the 1st and 10th transfers. For isolates from parent PCAS1, the order of sensitivity changed after 10 transfers. Three mutants (RZ13-3, RZ3-4, and R1-13) had increased resistance, whereas seven mutants (RZ2-8, RZ4-1, RZ2-2, RZ2-6, RZ3-3, RZ3-5, and R1-63) had decreased resistance to zoxamide (Table 2). The three isolates from parent $\mathrm{Hx}-1$ had increased zoxamide resistance after 10 transfers (Table 2). All isolates had RFs $>14$ regardless of parental isolates and how the mutants were generated (Table 2).

Mycelial growth responses to temperatures. The response of $P$. capsici isolates to different temperatures varied, and analysis of variance showed that effects of temperature $(P<0.0001)$, isolates
$(P<0.0001)$, and interaction of temperature-isolates were significant $(P<0.008)$ (Table 3$)$. Overall, $25^{\circ} \mathrm{C}$ was the optimal temperature for mycelial growth, regardless of isolate. The mycelial growth of mutants derived from PCAS1 asexually often was faster than PCAS1, with few exceptions, at 10 to $30^{\circ} \mathrm{C}$. However, at $35^{\circ} \mathrm{C}$, the growth of six isolates was slower, with two isolates remaining the same, compared with PCAS1 (Table 3). Mutants derived from Hx-1 asexually showed a slower growth or remained unchanged, compared with $\mathrm{Hx}-1$ at all five temperatures (Table 3 ). For the resistant isolates derived from sexual progeny, the growth of R1-63 was faster than PCAS1 at $18,25,30$, and $35^{\circ} \mathrm{C}$ and slower than PCAS 1 at $10^{\circ} \mathrm{C}$; and $\mathrm{R} 1-13$ grew significantly slower than its parents (PCAS1 and PCAS2) at all temperatures (Table 3).

Sporangial production and cystospore germination in vitro. For the mutants derived from asexual progeny with PCAS1 as a

TABLE 3. Mycelial growth of zoxamide resistant mutants of Phytophthora capsici and their parents at various temperatures on potato dextrose agar

\begin{tabular}{|c|c|c|c|c|c|}
\hline \multirow[b]{2}{*}{ Origin, isolate $^{\mathrm{y}}$} & \multicolumn{5}{|c|}{ Colony diameter $(\mathrm{mm})^{\mathrm{z}}$} \\
\hline & $10^{\circ} \mathrm{C}$ & $18^{\circ} \mathrm{C}$ & $25^{\circ} \mathrm{C}$ & $30^{\circ} \mathrm{C}$ & $35^{\circ} \mathrm{C}$ \\
\hline \multicolumn{6}{|l|}{ Asexual progeny } \\
\hline PCAS1 & 21.5 & 51.2 & 62.2 & 58.8 & 17.5 \\
\hline RZ4-1 & $28.3+$ & $53.3+$ & $59.0-$ & $62.8+$ & 16.0 \\
\hline RZ2-2 & 20.3 & 50.8 & $59.0-$ & 57.8 & $14.8-$ \\
\hline RZ2-6 & $24.5+$ & 49.5 & 60.0 & 59.2 & 16.2 \\
\hline RZ3-4 & $23.0+$ & $56.7+$ & $70.7+$ & $71.0+$ & $10.0-$ \\
\hline \multicolumn{6}{|l|}{ Asexual progeny } \\
\hline Hx-1 & 17.5 & 51.5 & 63.5 & 58.3 & 16.5 \\
\hline RZ19-10 & $15.3-$ & 50.5 & 61.5 & 59.5 & 15.8 \\
\hline Xh38-10 & $13.3-$ & $47.5-$ & $59.0-$ & $54.8-$ & $12.8-$ \\
\hline RZ4-2 & $12.8-$ & $46.8-$ & $58.0-$ & $53.8-$ & $12.8-$ \\
\hline
\end{tabular}

$\mathrm{y}$ Isolates in bold font are parents of the isolates listed under them.

${ }^{\mathrm{z}}$ Colony diameters were measured after 5 days of incubation in the dark. Mean values of the isolates within a column (separated by a solid line) were compared with their parents; + and - indicate faster or slower growth, respectively, than the parent $(\alpha=0.05)$. Isolate R1-63 was derived from selfed PCAS1 and R1-13 was derived from the cross between PCAS1 and PCAS2.

TABLE 4. Fitness of zoxamide-resistant and -sensitive isolates of Phytophthora capsici ${ }^{y}$

\begin{tabular}{|c|c|c|c|c|c|}
\hline Origin, isolate $^{z}$ & $\begin{array}{c}\text { Sporangia in vitro } \\
\left(\times 10^{5} / \mathrm{cm}^{2}\right)\end{array}$ & $\begin{array}{c}\text { Cystospore } \\
\text { germination }(\%)\end{array}$ & $\begin{array}{c}\text { Lesion area } \\
\text { on leaves }\left(\mathrm{cm}^{2}\right)\end{array}$ & $\begin{array}{l}\text { Sporangia in vivo } \\
\left(\times 10^{5} / \mathrm{cm}^{2}\right)\end{array}$ & $\begin{array}{c}\text { Oospore } \\
\left(\times 10^{5} / \text { plate }\right)\end{array}$ \\
\hline \multicolumn{6}{|l|}{ Asexual progeny } \\
\hline PCAS1 & $1.65 \mathrm{bc}$ & $72.50 a b$ & $8.58 \mathrm{ab}$ & $0.17 \mathrm{~b}$ & $2.0 \mathrm{ab}$ \\
\hline RZ4-1 & $2.33 \mathrm{ab}$ & $76.70 \mathrm{ab}$ & $11.56 \mathrm{a}$ & $0.10 \mathrm{~b}$ & $2.8 \mathrm{a}$ \\
\hline RZ2-2 & $1.33 \mathrm{bc}$ & $79.70 \mathrm{a}$ & $11.16 \mathrm{a}$ & $0.06 \mathrm{c}$ & $2.4 \mathrm{ab}$ \\
\hline RZ2-6 & $0.50 \mathrm{c}$ & $76.70 \mathrm{ab}$ & $12.78 \mathrm{a}$ & $0.08 \mathrm{bc}$ & $1.9 \mathrm{ab}$ \\
\hline RZ13-3 & $3.65 \mathrm{a}$ & $65.50 \mathrm{ab}$ & $3.00 \mathrm{~b}$ & $0.32 \mathrm{a}$ & $1.5 \mathrm{~b}$ \\
\hline RZ3-4 & $0.83 \mathrm{bc}$ & $62.90 \mathrm{ab}$ & $6.86 \mathrm{ab}$ & $0.09 \mathrm{bc}$ & $2.6 \mathrm{a}$ \\
\hline Hx-1 & $3.50 \mathrm{~b}$ & $37.00 \mathrm{~b}$ & $7.68 \mathrm{~b}$ & $0.98 \mathrm{~b}$ & $0.7 \mathrm{~b}$ \\
\hline RZ19-10 & $16.00 \mathrm{a}$ & $82.50 \mathrm{a}$ & $9.52 \mathrm{a}$ & $1.58 \mathrm{~b}$ & $0.6 \mathrm{~b}$ \\
\hline Xh38-10 & $14.00 \mathrm{a}$ & $77.00 \mathrm{a}$ & $7.33 \mathrm{~b}$ & $1.43 \mathrm{~b}$ & $1.2 \mathrm{a}$ \\
\hline RZ4-2 & $8.00 \mathrm{~b}$ & $69.50 \mathrm{a}$ & $3.30 \mathrm{c}$ & $2.73 \mathrm{a}$ & $0.5 \mathrm{~b}$ \\
\hline \multicolumn{6}{|l|}{ Sexual progeny } \\
\hline
\end{tabular}

${ }^{y}$ Sporulation was measured as sporangia per square centimeter of lesion. Means of each measurement in the same column and under each parent (separated by solid lines) followed by same letters are not significantly different according to Fisher's least significance difference $(\alpha=0.05)$.

${ }^{\mathrm{z}}$ Isolates in bold font are parents of the mutant isolates listed under them. 
parent, all isolates had no differences for sporangial production, except that RY13-3 had significantly higher sporulation. For mutants derived from Hx-1, RZ19-10 and Xh38-10 produced significantly more sporangia but RZ4-2 showed no significant difference compared with the parental strain. For mutants derived from sexual progeny, sporangial production of R1-63 was not different from the parental strain PCAS1; sporangial production of R1-13 was significantly higher than PCAS1 but was not significantly different from PCAS2 (Table 4).

Cystospore germination of the PCAS1-derived mutants was not significantly different from their parental strain except that RZ3-3 had a lower germination rate. For mutants derived from $\mathrm{Hx}-1$, all three isolates showed significantly higher cystospore germination than the parental strain. For mutants derived from sexual progeny, cystospore germination of R1-63 was significantly lower than PCAS1 but R1-13 was higher than both parents (Table 4).

Virulence and sporulation of $\mathrm{P}$. capsici isolates in vivo. Both zoxamide-sensitive and -resistant isolates caused typical and severe symptoms on detached pepper leaves. All mutants caused similar size lesions (no significant differences) compared with their parental isolates, except that the lesion caused by RZ19-10 was significantly larger and the lesion caused by RZ4-2 was significantly smaller than that caused by Hx-1 (Table 4). Similarly, sporulation production on leaves showed some differences
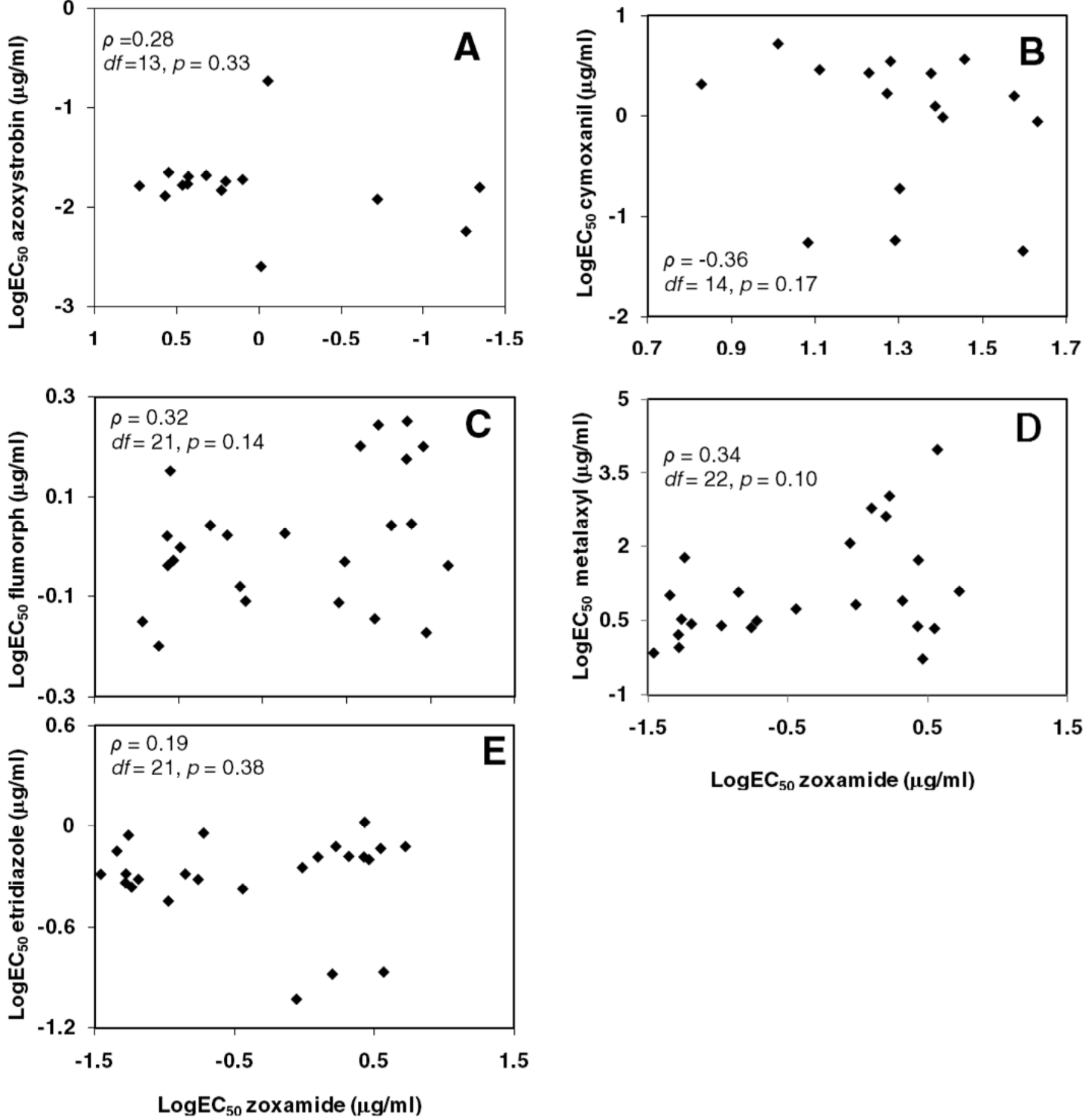

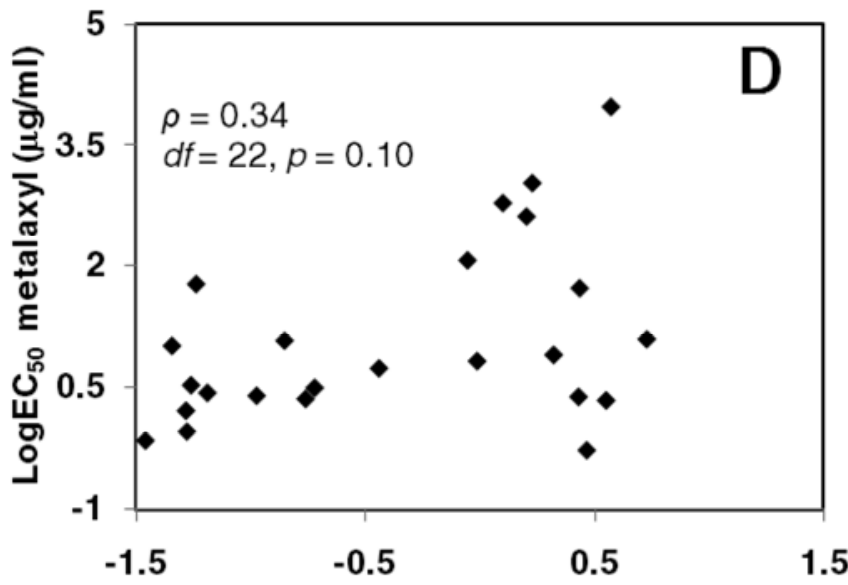

$\operatorname{LogEC} \mathrm{E}_{50}$ zoxamide $(\mu \mathrm{g} / \mathrm{ml})$

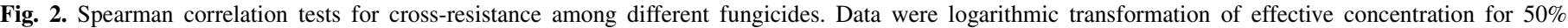

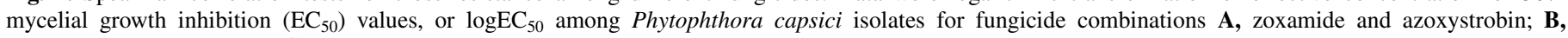
zoxamide verses cymoxanil; $\mathbf{C}$, zoxamide verses flumorph; D, zoxamide verses metalaxyl; and $\mathbf{E}$, zoxamide verses etridiazole. 
between a few isolates and their parents. Mutants RZ13-3 and RZ4-2 produced more sporangia than their parents PCAS1 and Hx-1, respectively. Mutants RZ2-8, RZ2-2, and R1-13 produced significantly fewer sporangia than their parent PCAS1. The rest of the isolates were not significantly different in sporulation compared with their parental strains.

Mating types and oospore production of $\mathrm{P}$. capsici mutants. All but one of the resistant isolates was positive for the A1 mating type. The exception was R1-13, which was A2. The majority of the mutants had no significant differences for oospore production compared with the parental strains. The exceptions were Xh3810, which produced more oospores than $\mathrm{Hx}-1$, while R1-63 and R1-13 produced fewer than PCAS1 (Table 4).

Cross-resistance. All the resistant mutants; parental strains PCAS1, Hx-1, and PCAS2; and randomly selected wild-type isolates were tested for resistance to several fungicides. No crossresistance was detected between zoxamide and any of the fungicides, including azoxystrobin, cymoxanil, flumorph, metalaxyl, or etridiazole $(\rho<0.36, P>0.05)$ (Fig. 2).

\section{DISCUSSION}

In this study, a baseline sensitivity of the $P$. capsici population to zoxamide has been established. We also have produced and characterized $P$. capsici mutants resistant to zoxamide. The $\mathrm{EC}_{50}$ values showed a range of distribution of 0.023 to $0.383 \mu \mathrm{g} / \mathrm{ml}$ for the isolates from 11 geographical origins but all showed sensitivity to zoxamide. This result was similar to zoxamide sensitivity observed in $P$. capsici isolates collected from South Carolina (14). Because no zoxamide has been applied in the field in China before $P$. capsici was collected, all 158 field isolates of $P$. capsici from different geographical districts collected during 2007 to 2009 were sensitive to zoxamide, and no spontaneous mutants in nature were detected. Therefore, the result of zoxamide sensitivity can be used to provide a baseline for monitoring sensitivity changes in $P$. capsici populations to zoxamide.

Zoxamide-resistant mutants of $P$. capsici have not been reported in natural populations to date but, according to our results, the risk of resistance development should be addressed. The incidence of zoxamide resistance may be affected by the frequent applications of the fungicide, which is supported by our data that repeated transfer of $P$. capsici culture on zoxamide-amended media generated resistant mutants, and the mutation selection was $\approx 10^{-7}$. This frequency is much higher than that of $P$. capsici responding to iprovalicarb (17) but lower than that of $P$. capsici responding to dimethomorph, with a mutation frequency of $0.5 \%$ (29), and that of P. capsici SCC1 and SCC2 to dimethomorph, with a mutation frequency of 14 and $18 \%$ (34). We successfully generated $P$. capsici mutants with high resistance to zoxamide $(\mathrm{RF}=147.8)$ compared with the levels of resistance reported in a study by Young et al. ( RF < 2.2) (33). More importantly, the mutants we generated had a stable zoxamide resistance after as many as 10 transfers or via sexual reproduction (ongoing studies, unpublished) and competitive fitness components.

The absence of cross-resistance between zoxamide and metalaxyl, flumorph, cymoxanil, azoxystrobin, or etridiazole indicates different modes of action of zoxamide versus these other fungicides. Zoxamide acts on microtubules of the pathogen, and has been ascribed to be a low-risk fungicide for resistance development in the pathogen (33). As a comparison, fungicides in the benzimidazoles group, including benomyl, carbendazim, and thiabendazole, disrupt microtubules by binding to $\beta$-tubulin. Tubulin mutants with high levels of resistance to benzimidazoles have been readily obtained in the laboratory, and are responsible for serious resistance problems in the field $(7,9)$. The major difference between benzimidazoles and zoxamide is that the latter is active primarily toward the diploid oomycetes (27), while benzimidazoles target on haploid true fungi. It has been proposed that $P$. capsici mutants resistant to zoxamide are likely to have a recessive phenotype (33). That means the mutants must be homozygous for the allele for the resistance to be fully expressed. This may be the situation in our case. The zoxamide-resistant mutants were obtained at a low frequency in asexual progeny and some isolates could not even generate such mutants; however, the frequency of resistance was much higher in sexual progeny than asexual progeny. This could indicate that the wild-type isolate PCAS1 may be a heterozygous isolate that contains a resistant allele. Therefore, genetic background of parental strains used for mutant selection is critical and could be a factor in the field population for mutant development. To confirm these idiosyncratic characteristics of the isolates, a genetic study of the resistance by crossing different isolates is being investigated in our laboratory.

Sexual reproduction can occur when isolates with opposite mating types (A1 and A2) exist in the field simultaneously. It has been observed that the ratio of A1 and A2 mating types of $P$. capsici is nearly $1: 1$ in the field in the United States (13). A1 and A2 co-exist in many areas, and three mating types (A1, A2, and A1A2) are present in Gansu province in China (16). Thus, in locations where both $\mathrm{A} 1$ and $\mathrm{A} 2$ mating types are present or the pathogens of the two mating types are transported from infested field to another place via irrigation water (11), the population could reproduce sexually. The risk of rapid resistance development to zoxamide could be significantly higher by gene recombination.

Zoxamide blocks nuclear division by disrupting microtubules in the pathogen as the result of covalent binding to the $\beta$-subunit of tubulin (32) but changes in the $\beta$-tubulin may not fully explain the resistance mechanisms in oomycetes and fungi. Malandrakis et al. (19) suggested that a single amino acid substitution in position 198 of the $\beta$-subunit gene mediates the response to zoxamide from being hypersensitive to sensitive and highly resistant in $B$. cinerea. However, the nucleotide sequence of the gene coding the $\beta$-subunit of tubulin of $P$. capsici mutants was not different compared with the parental wild-type isolate (unpublished). Therefore, there might be another mechanism of resistance involved in $P$. capsici, such as reduced uptake, detoxification of the fungicide, or overproduction of the target protein (8). As such, the quantification of transcription of the $\beta$-subunit of the tubulin gene in the parental wild-type isolate and zoxamideresistant mutants of $P$. capsici on the mRNA level or expression in protein level should be examined in future work. The lack of resistance to other fungicides in resistant mutants could indicate that this probably is not due to an efflux pump.

Fungicide-resistant mutants can survive in the environment in the pressure of the fungicide they are resistant to but, in most cases, this mutational change leads a fitness penalty for the pathogen, resulting in the mutants being less aggressive and competitive in nature (36). This can help to slow down the development of fungicide resistance in the field population. However, in this case, fitness of most zoxamide-resistant mutants of $P$. capsici was almost unaffected, with some variations, in that some isolates had higher and some had lower growth components, although the differences were statistically significant. This suggests that the genetic link between fitness characteristics and resistance to zoxamide in $P$. capsici is not strong, or may not even be associated. This will increase the possibility of risk for zoxamide-resistance development.

Based on all of these results - that no fitness penalty has been observed, that $P$. capsici has high frequency in sexually reproducing populations, and that there was persistent resistance in subsequent generations-we conclude that the risk of developing resistance to zoxamide in $P$. capsici is moderate (determined by ease of mutation and survival ability) in theory. To avoid a quick development of zoxamide resistance in the field, appropriate resistance-management strategies are needed, including moni- 
toring changes in $P$. capsici sensitivity over time and alternating zoxamide with other oomycete-specific fungicides, such as dimethomorph, mandipropamid, and other carboxylic acid amides fungicides. Because no cross resistance was observed and different modes of actions are present, fungicides such as azoxystrobin, cymoxanil, etridiazole, and flumorph could be good candidates for rotation with zoxamide.

\section{ACKNOWLEDGMENTS}

This work was partially funded by the National Science Foundation of China (grant number 30800731) and the Doctor Foundation of the State Ministry of Education, China (grant number200800190025), and the United States Department of Agriculture Specialty Crop Research Initiative program (NIFA grant number 2008-51180-04881). We thank L. Hanson for providing a deep revision and critique on the manuscript.

\section{LITERATURE CITED}

1. Bower, L. A., and Coffey, M. D. 1985. Development of laboratory tolerance to phosphorus acid, fosetyl-al, and metalaxyl in Phytophthora capsici. Can. J. Plant Pathol. 7:1-6.

2. Brandt, U., Schagger, H., and Jagow, V. G. 1988. Characterization of binding of themethoxyacrylate inhibitors to mitochondrial cytochrome creductase. Eur. J. Biochem. 173:499-506.

3. Cafe, A. C., and Ristaino, J. B. 2008. Fitness of isolates of Phytophthora capsici resistant to mefenoxam from squash and pepper fields in North Carolina. Plant Dis. 92:1439-1443.

4. Chen, Y., Shen, C. Y., and Duan, D. H. 1988. The main causes Phytophthora capsici as one of capsicum plant wilt in Beijing region. Acta Phytopathol. Sin. 18:7-11.

5. Cohen, Y., Rubin, E., Hadad, T., Gotlieb, D., Sierotzki, H., and Gisi, U. 2007. Sensitivity of Phytophthora infestans to mandipropamid and the effect of enforced selection pressure in the field. Plant Pathol. 56:836-842.

6. Davidse, L. C., Hofman, A. E., and Velthuis, G. C. M.1983. Specific interference of metalaxyl with endogenous RNA polymerase activity in isolated nuclei from Phytophthora megasperma f. sp. medicaginis. Exp. Mycol. 7:344-361.

7. Davidse, L. C., and Ishii, H. 1999. Biochemical and molecular aspects of the mechanisms of action of benzimidazoles, $\mathrm{N}$-phenylcarbamates and $\mathrm{N}$ phenylformamidoximes and the mechanisms of resistance to these compounds in fungi. Pages 305-322 in: Modern Selective Fungicides: Properties, Applications, Mechanisms of Action. H. Lyr, ed. Gustav Fischer Verlag, New York.

8. Dekker, J. 1995. Development of resistance to modern fungicides and strategies for its avoidance. Pages 23-28 in: Modern Selective Fungicides: Properties, Applications, Mechanisms of Action. H. Lyr, ed. Gustav Fischer Verlag, New York.

9. Delp, C. J. 1995. Benzimidazole and related fungicides. Pages 291-303 in: Modern Selective Fungicides: Properties, Applications, Mechanisms of Action. H. Lyr, ed. Gustav Fischer Verlag, New York.

10. Egan, A. R., Michelotti, E. L., Young, D. H., Wilson, W. J., and Mattioda, H. 1998. RH-7281: a novel fungicide for control of downy mildew and late blight. Pages 335-342 in: Proc. Brighton Crop Prot. Conf. Pests Dis. Vol. 2. BCPC Publications, Croydon, UK.

11. Erwin, D. C., and Ribeiro, O. K. 1996. Pages 250-266 in: Phytophthora Diseases Worldwide. American Phytopathological Society, St. Paul, MN.

12. Granke, L. L., Windstam, S. T., Hoch, H. C., Smart, C. D., and Hausbeck, M. K. 2009. Dispersal and movement mechanisms of Phytophthora capsici sporangia. Phytopathology 99:1258-1264.

13. Hausbeck, M. K., and Lamour, K. H. 2004. Phytophthora capsici on vegetable crops: research progress and management challenges. Plant Dis. 88:1292-1303.

14. Keinath, A. P. 2007. Sensitivity of populations of Phytophthora capsici from South Carolina to mefenoxam, dimethomorph, zoxamide, and cymoxanil. Plant Dis. 91:743-748.

15. Lamour, K. H., and Hausbeck, M. K. 2000. Mefenoxam insensitivity and the sexual stage of Phytophthora capsici in Michigan cucurbit fields.
Phytopathology 90:396-400.

16. Liu, Y. G., Zhang, H. Y., Guo, J. G., Lv, H. P., He, C. G., and Song, S. Y. 2008. Mating type distribution and pathogenicity difference of Phytophthora capsici in Gansu. Acta Phytopathol. Sin. 35:448-452.

17. Lu, X. H., Zhu, S. S., Bi, Y., Liu, X. L., and Hao, J. J. 2010. Baseline sensitivity and resistance-risk assessment of Phytophthora capsici to iprovalicarb. Phytopathology 100:1162-1168.

18. Luo, H. R., Xie, B. Y., Ma, F. H., and Zhu, G. R. 1999. A study on Phytophthora capsici's genetic resistance to metalaxy and cymoxianil. J. Hunan Agric. Univ. 25:52-56.

19. Malandrakis, A., Markoglou, A., and Ziogas, B. 2010. Molecular characterization of benzimidazole-resistant $B$. cinerea field isolates with reduced or enhanced sensitivity to zoxamide and diethofencarb. Pestic. Biochem. Physiol. doi: 10.1016/j.pestbp.2010.11.008.

20. Martinez, C., Levesque, C. A., Belanger, R. R., and Tweddell, R. J. 2005. Evaluation of fungicides for the control of carrot cavity spot. Pest Manage. Sci. 61:767-771

21. Miller, J. S., Olsen, N., Woodell, L., Porter, L. D., and Clayson, S. 2006. Post-harvest applications of zoxamide and phosphite for control of potato fiber rots caused by oomycetes at harvest. Am. J. Potato Res. 83:269-278.

22. Oelke, L. M., Bosland, P. W., and Steiner, R. 2003. Differentiation of race specific resistance to Phytophthora root rot and foliar blight in Capsicum аппиит. J. Am. Society Hortic. Sci. 128:213-218.

23. Parra, G., and Ristaino, J. B. 2001. Resistance to mefenoxam and metalaxyl among field isolates of Phytophthora capsici causing Phytophthora blight of bell pepper. Plant Dis. 85:1069-1075.

24. Porter, L. D., Hamm, P. B., David, N. L., Gieck, S. L., Miller, J. S., Gundersen, B., and Inglis, D. A. 2009. Metalaxyl-M-resistant Pythium species in potato production areas of the Pacific Northwest of the USA. Am. J. Potato Res. 86:315-326.

25. Ristaino, J. B., Larkin, R. P., and Campbell, C. L. 1994. Spatial dynamics of disease symptom expression during Phytophthora epidemics in bell pepper. Phytopathology 84:1015-1024.

26. Rubin, A., Gotlieb, D., Gisi, U., and Cohen, Y. 2008. Mutagenesis of Phytophthora infestans for resistance against carboxylic acid amide and phenylamide fungicides. Plant Dis. 92:675-683.

27. Shaw, D. S. 1988. The cytogenetics and genetics of Phytophthora. Pages 20-21 in: Phytophthora: Its Biology, Taxonomy, Ecology, and Pathology. D. C. Erwim, S. Bartnicki-Garcia, and P. H. Tsao, eds. American Phytopathological Society, St. Paul, MN.

28. Silvar, C., Merino, F., and Diaz, J. 2006. Diversity of Phytophthora capsici in northwest Spain: analysis of virulence, metalaxyl response, and molecular characterization. Plant Dis. 90:1135-1142.

29. Sun, H. Y., Wang, H. C., Stammler, G., Ma, J. X., and Zhou, M. G. 2010. Baseline sensitivity of populations of Phytophthora capsici from China to three carboxylic acid amide (CAA) fungicides and sequence analysis of cholinephosphotranferases from a CAA-sensitive isolate and CAAresistant laboratory mutants. J. Phytopathol. 158:244-252.

30. Young, D. H. 2007. Zoxamide, an antitubulin fungicide for control of oomycete pathogens. Pages 581-590 in: Modern Crop Protection Compounds. W. Kramer and U. Schirmer, eds. Wiley-VCH Verlag GmbH \& Co., KGaA, Weinheim, Germany.

31. Young, D. H., Rubio, F. M., and Danis, P. O. 2006. A radioligand binding assay for antitubulin activity in tumor cells. J. Biomol. Screen 11:82-89.

32. Young, D. H., and Slawecki, R. A. 2001. Mode of action of zoxamide (RH-7281), a new oomycete fungicide. Pestic. Biochem. Physiol. 69:100111.

33. Young, D. H., Spiewak, S. L., and Slawecki, R. A. 2001. Laboratory studies to assess the risk of development of resistance to zoxamide. Pest Manage. Sci. 57:1081-1087.

34. Yuan, S. K., Liu, X. L., Gu, B. G., Dong, J., Jiang, H., and Si, N. G. 2005. Induction and characterization of laboratory mutants of Phytophthora capsici resistant to dimethomorph and flumorph. Agric. Sci. China 4:752-759.

35. Zhu, J. H., Zhang, Z. M., and Li, Y. Q. 2000. Distribution of the A2 mating type of potato late blight pathogen ( Phytophthora infestans). Acta Phytopathol. Sin. 30:37-51.

36. Ziogas, B. N., Markoglou, A. N., Theodosiou, D. I., Anagnostou, A., and Boutopoulou, S. 2006. A high multi-drug resistance to chemically unrelated oomycete fungicides in Phytophthora infestans. Eur. J. Plant Pathol. 115:283-292. 